\title{
COMPARISON OF ASSOCIATED AND DISPERSED TESTERS IN THE TRIPLE TEST CROSS
}

\author{
H. S. POONI AND J. L. JINKS \\ Department of Genetics, University of Birmingham, Birmingham B15 2TT, U.K.
}

Received 29.ix.82

\begin{abstract}
SUMMARY
The theoretical consequences of using inbred testers for an $F_{2}$ and $F_{\infty}$ triple test cross in which the allelic differences are associated as opposed to dispersed are described for four situations of increasing complexity that arise from the presence of non-allelic interaction and a linkage disequilibrium either singly or jointly. The theoretical expectations are confirmed by analyses of two $F_{\infty}$ triple test crosses on a random sample of 60 inbred families from the cross of varieties 2 and 12 of Nicotiana rustica for which the inbred testers are the two varieties and the two extremes of the 60 inbred families in respect of final height and flowering time.

In the presence of non-allelic interaction and a linkage disequilibrium between interacting or non-interacting genes, the expectations of the mean squares in the analysis of variance of a triple test cross and of the estimates of the additive genetic, dominance and epistatic components obtained from them, differ characteristically according to whether a dispersed or an associated pair of inbred testers have been used. The pattern of the differences can, therefore, be used to detect these complex effects.

Comparison of the corresponding mean squares and estimates from the two $F_{\infty}$ triple test crosses shows that non-allelic interactions and a linkage disequilibrium are present but there is no significant evidence that the disequilibrium involves interacting genes.
\end{abstract}

\section{INTRODUCTION}

Comparison of the basic generations of a matched pair of crosses whose pure breeding parents display association and dispersion for the same alleles at the same loci provides sensitive tests for the presence of epistasis and linkage disequilibrium (Pooni and Jinks, 1982). In this paper we extend this comparison to the triple test cross (Kearsey and Jinks, 1968). In the absence of epistasis and a linkage disequilibrium the expectations of the components of variation in a triple test cross analysis are the same irrespective of whether the alleles are associated or dispersed in the pure breeding testers $\mathrm{L}_{1}$ and $\mathrm{L}_{2}$. In their presence this is no longer true as we shall show by deriving the appropriate theoretical expectations. Comparative triple test cross analyses of the same population, a random sample of highly inbred lines from the cross of varieties 2 and 12 of Nicotiana rustica, using dispersed and associated testers will be used to illustrate the theory.

\section{Theoretical expectations}

Expectations have been obtained for a single pair of loci at which the alleles are either associated $(A A B B$ and $a a b b)$ or dispersed ( $A A b b$ and $a a B B$ ) in the pure breeding testers. The populations under test are the $F_{2}$ and $F_{\infty}$ generations of a cross between two pure breeding lines in which 


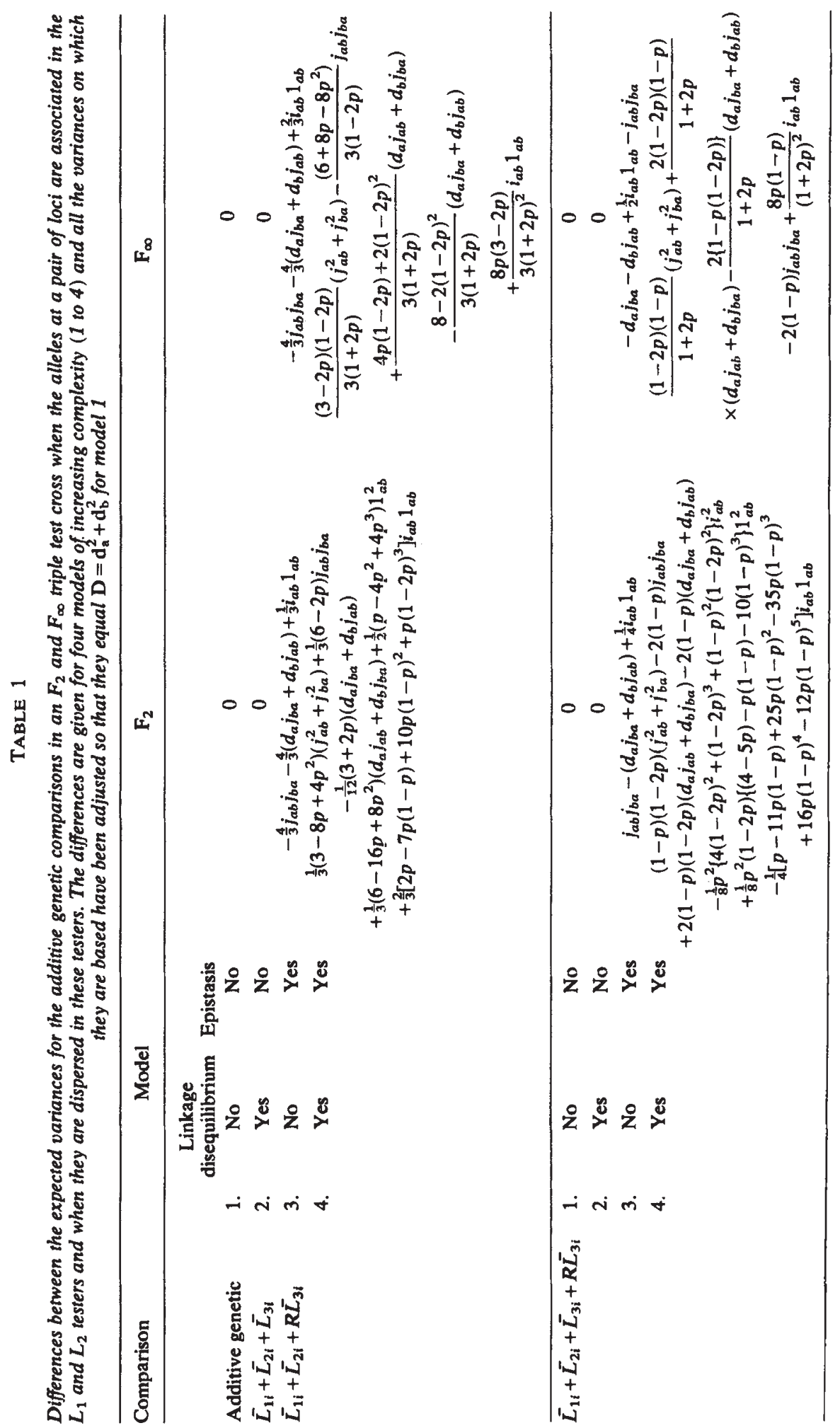




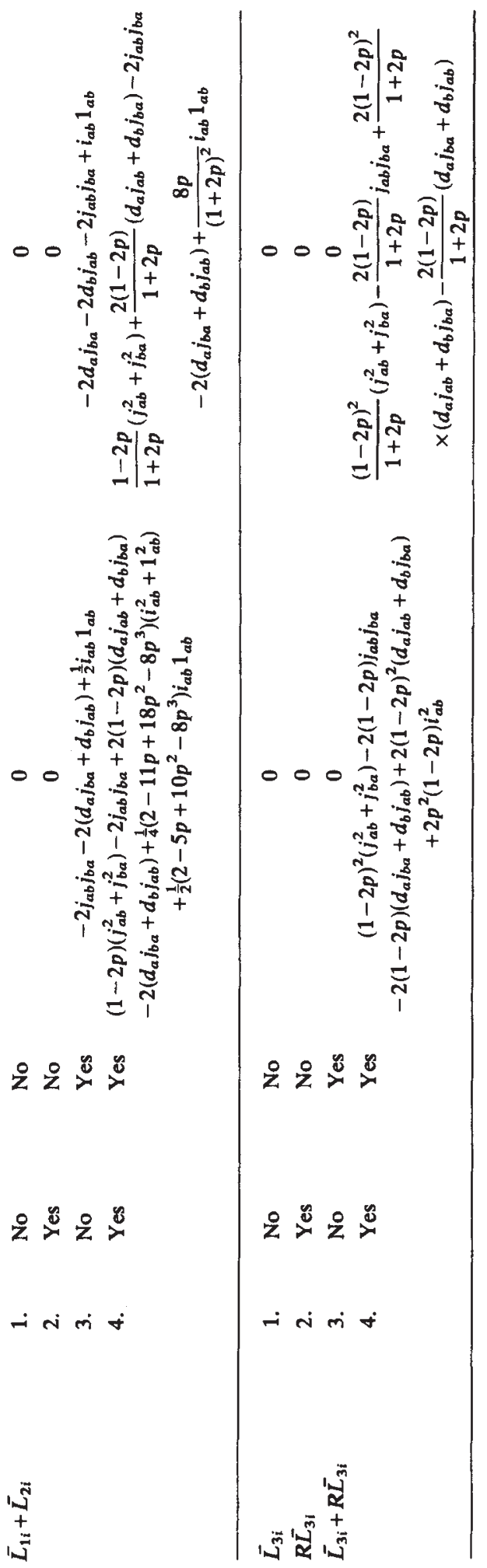


the alleles at these pair of loci are dispersed. Four levels of complexity of the genetical variation in these populations are considered:

(a) No epistasis and linkage equilibrium.

(b) No epistasis and linkage disequilibrium.

(c) Epistasis and linkage equilibrium.

(d) Epistasis and linkage disequilibrium.

The differences between the expected variances derived from the standard comparisons used in triple test cross analysis for the associated and dispersed testers using the standard symbols of biometrical genetics (Mather and Jinks, 1982) are tabulated as follows:

Table 1: the additive genetic comparisons $\left(\bar{L}_{1 i}+\bar{L}_{2 i}+\bar{L}_{3 i}\right),\left(\bar{L}_{1 i}+\bar{L}_{2 i}+\right.$ $\left.\overline{R L}_{3 i}\right),\left(\bar{L}_{1 i}+\bar{L}_{2 i}+\bar{L}_{3 i}+\overline{R L}_{3 i}\right),\left(\bar{L}_{1 i}+\bar{L}_{2 i}\right),\left(\bar{L}_{3 i}\right),\left(\overline{R L}_{3 i}\right)$ and $\left(\bar{L}_{3 i}+R \bar{L}_{3 i}\right)$.

Table 2: the epistasis comparisons $\left(\bar{L}_{1 i}+\bar{L}_{2 i}-2 \bar{L}_{3 i}\right),\left(\bar{L}_{1 i}+\bar{L}_{2 i}-2 R \bar{L}_{3 i}\right)$ and $\left(\bar{L}_{1 i}+\bar{L}_{2 i}-\bar{L}_{3 i}-R \bar{L}_{3 i}\right)$ and the dominance comparison $\left(\bar{L}_{1 i}-\bar{L}_{2 i}\right)$.

To make all of these expectations directly comparable, irrespective of the number and coefficients of the $L_{1 i}, L_{2 i}, L_{3 i}$ and $R L_{3 i}$ family means involved in their derivation and whether they relate to an $F_{2}$ or an $F_{\infty}$ population, they have been adjusted so that the epistatic comparisons equal $I=i_{a b}^{2}$ and the additive genetic and dominance comparisons equal $D=$ $d_{a}^{2}+d_{b}^{2}$ and $H=h_{a}^{2}+h_{b}^{2}$ for a linkage equilibrium and no epistasis. For example, the first comparison in table 1 is $\bar{L}_{1 i}+\bar{L}_{2 i}+\bar{L}_{3 i}$ which has an expected mean square in the standard analysis of variance of $\sigma^{2}+3 r \sigma_{s}^{2}$, where $\sigma^{2}$ is the error component, $r$ is the number of replicates and $\sigma_{s}^{2}$ is the "sums" component which on the simplest model has the expectation $\frac{1}{8} D$ for an $F_{2}$ and $\frac{1}{4} D$ for an $\mathrm{F}_{\infty}$ triple test cross. The adjusted variances of table 1 are, therefore $8 \sigma_{s}^{2}$ for the $\mathrm{F}_{2}$ and $4 \sigma_{s}^{2}$ for the $\mathrm{F}_{\infty}$ and the differences tabulated are $8\left[\left(\sigma_{s}^{2}\right.\right.$ for the associated testers $)-\left(\sigma_{s}^{2}\right.$ for the dispersed testers)] for the $F_{2}$ and half of this for the $F_{\infty}$.

Reference to tables 1 and 2 shows that in the absence of epistasis (models 1 and 2 ) the expectations of the additive genetic component are independent of whether the alleles are associated or dispersed in the inbred testers, $L_{1}$ and $L_{2}$. Hence in the absence of epistasis estimates of the additive component $D$ are expected to be the same irrespective of the distribution of the alleles between the testers. Furthermore, if the additive genetic component is obtained from the $\bar{L}_{3 i}, R \bar{L}_{3 i}$ and $\bar{L}_{3 i}+R \bar{L}_{3 i}$ comparisons it is independent of the allelic distribution between the testers even in the presence of epistasis provided that there is no linkage disequilibrium among the interacting alleles.

In contrast the expectation of the dominance comparison and hence the estimate of the dominance component $H$ is independent of the allelic distribution between the testers only if neither epistasis nor a linkage disequilibrium are present. On the other hand, the expectations of the epistasis comparisons are independent of the allelic distribution between the testers irrespective of whether epistasis or a linkage disequilibrium are present.

For the additive genetic and dominance comparisons these expectations can be directly extended to many pairs of loci, each pair contributing the difference specified in tables 1 and 2 . This is not, however, the case for all of the epistasis comparisons. In the presence of epistasis (models 3 and 4) the overall epistasis variance for 1 degree of freedom after adjustment has 


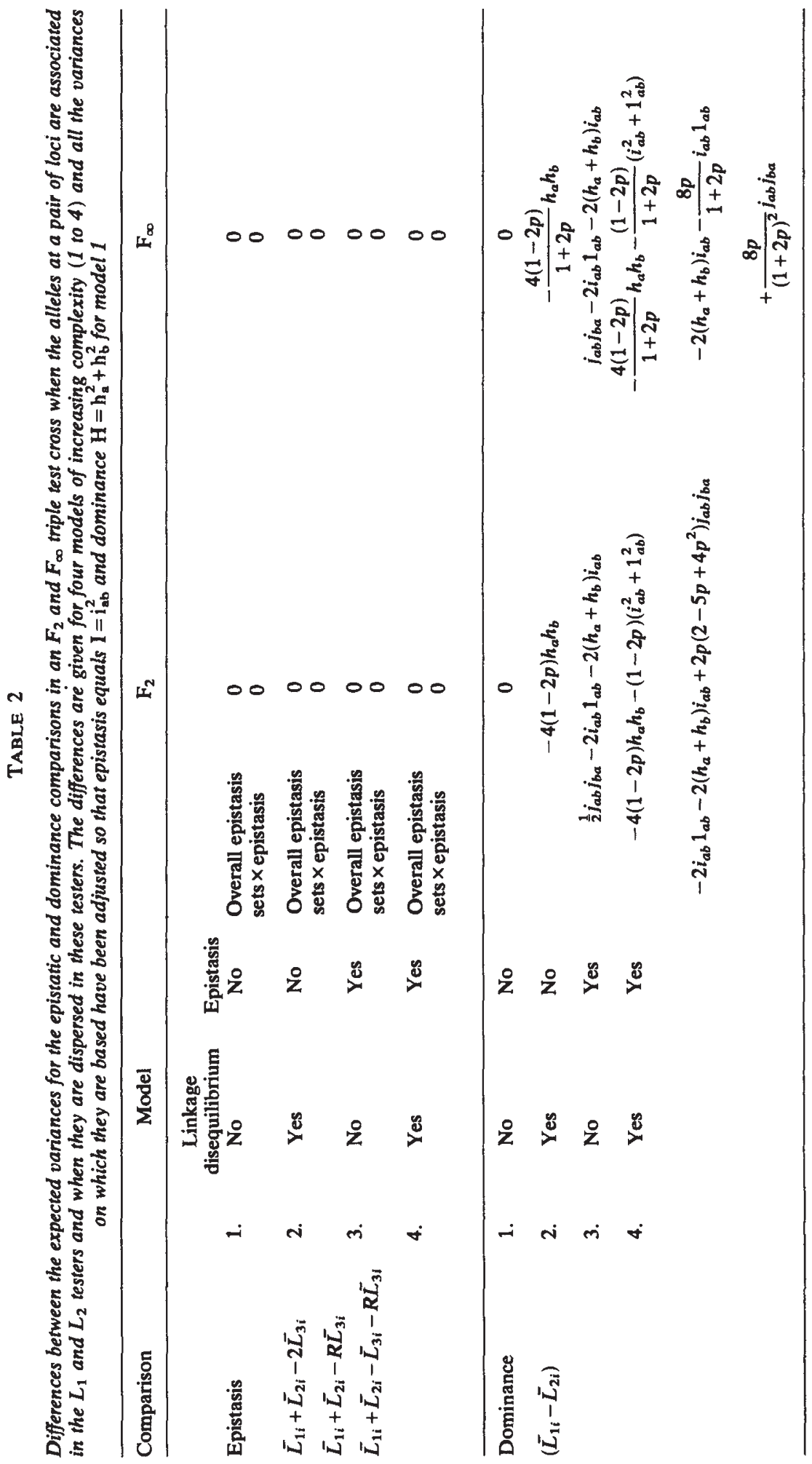


the general form $\left[r_{i} \sum_{i}^{i k(k-1)}\right]^{2}$ (Mather and Jinks, 1982) where $r_{i}$, the coefficient of association and dispersion equals 1 when all contributing pairs are associated, 0 when associated and dispersed pairs are contributing equally and -1 when all contributing pairs are dispersed. The maximum difference between the adjusted epistasis variances for models 3 and 4 is, therefore, $\left(\sum_{i}^{\frac{1}{1} k(k-1)}\right)^{2}$.

The patterns of expected differences for the additive and dominance comparisons in tables 1 and 2 provide diagnostic tests for a linkage disequilibrium and non-allelic interactions. For example:

(a) If no difference is significant, neither a linkage disequilibrium nor non-allelic interaction is making a significant contribution (model 1).

(b) If only the dominance comparison difference is significant, a linkage disequilibrium involving loci which are not displaying non-allelic interactions is making a significant contribution (model 2).

(c) If all differences are significant with the exception of those for the additive genetic comparisons $\bar{L}_{3 i}, \overline{R L}_{3 i}$ and $\left(\bar{L}_{3 i}+\overline{R L}_{3 i}\right)$, nonallelic interactions are making a significant contribution but there is no linkage disequilibrium (model 3).

(d) If all differences are significant, there is a linkage disequilibrium involving loci displaying non-allelic interactions (model 4).

Because $h_{a}, h_{b}, i_{a b}, j_{a b}, j_{b a}$ and $1_{a b}$ can all take sign, the signs of the differences are not particularly helpful in discriminating between the various models. One exception is the dominance comparison for model 2 . With dominance in the same direction at the linked loci the difference is negative but if it is in opposite directions the difference is positive.

\section{MATERIAL AND EXPERIMENTAL DESIGN}

Allelic differences for flowering time and final height are relatively dispersed between varieties 2 and 12 of Nicotiana rustica. Estimates of their coefficient of association/dispersion by the method of Jayasekara and Jinks (1976) were 0.52 and 0.35 , respectively (Pooni and Jinks, 1982) where 0 is complete dispersion and 1 complete association. Among the random sample of the 60 inbred families derived by single seed descent from the $F_{2}$ of the cross of V2 and V12 by Perkins and Jinks (see Jinks, Jayasekara and Boughey, 1977) were two inbred lines D10 and D17 which had the extreme combination of both characters with coefficients of association/dispersion of $\mathbf{0 . 7 7}$ for flowering time and 1.00 for final height (Pooni and Jinks, 1982).

Two $F_{\infty}$ triple test crosses were set up in 1974 using the $60 \mathrm{D}$ inbred families and V2, V12 and their reciprocal $F_{1}$ 's as the dispersed set of testers and D10, D17 and their reciprocal $F_{1}$ 's as the associated set of testers with respect to flowering time and final height. Five plants of each of the $60 \times 8$ test cross families and of the 60D families were raised in 1975 in each of two replicate blocks in which all 2700 plants in each block were individually randomised and scored for the two characters. Because there were no significant block interactions the five plants of each family in each block were pooled in the analyses.

The standard triple test cross design using V2, V12 and one $F_{1}(V 2 \times$ V12) as testers, which can be extracted from the 1975 experiment, has 
previously been described and analysed by Pooni, Jinks and Jayasekara (1978). The very small differences between the estimates presented in their table 3 and the corresponding ones presented later in this paper are due to the pooling of the two blocks.

\section{RESULTS}

The relevant mean squares of the triple test cross analysis including the alternative comparisons that are available for the additive genetic and epistasis components are given in tables 3 and 4 . They are standardised on the means of the ten individuals in each family. With but two exceptions, epistasis $\times$ sets $\left(\bar{L}_{1 i}+\bar{L}_{2 i}-2 R \bar{L}_{3 i}\right)$ comparison and overall epistatic $\left(\bar{L}_{1 i}+\right.$ $\left.\bar{L}_{2 i}-2 R \bar{L}_{3 i}\right)$ comparison using the V2 $\times$ V12 testers for flowering time, all the mean squares are significant $(P \equiv 0.05)$ most of them highly so $(P \equiv$ 0.001). Apart from the epistatic comparisons where the significances are higher for the $\mathrm{D} 10 \times \mathrm{D} 17$ than for the V2 $\times$ V12 testers there is no suggestion that the different testers are affecting the sensitivity of the tests.

Whether or not estimates of the additive genetic, dominance and epistatic components of variation differ significantly according to whether

TABLE 3

Mean squares and tests of significance for the additive genetic comparisons of an $F_{\infty}$ triple test cross with dispersed $(V 2, V 12)$ and associated $(D 10, D 17)$ inbred testers

\begin{tabular}{|c|c|c|c|c|c|c|c|c|}
\hline \multirow{2}{*}{$\begin{array}{l}\text { Inbred } \\
\text { testers }\end{array}$} & \multirow[b]{2}{*}{ Item } & \multirow[b]{2}{*}{ d.f. } & \multicolumn{3}{|c|}{ Flowering time } & \multicolumn{3}{|c|}{ Final height } \\
\hline & & & MS & $\chi_{(n)}^{2}$ & $P$ & MS & $\chi_{(n)}^{2}$ & $P$ \\
\hline \multicolumn{9}{|c|}{ (i) $\left(\bar{L}_{1 i}+\bar{L}_{2 i}+\bar{L}_{3 i}\right)$ Comparison } \\
\hline V2 V12 & $\begin{array}{l}\text { Between sets } \\
\text { Within families }\end{array}$ & $\begin{array}{r}59 \\
1608\end{array}$ & $\begin{array}{r}48 \cdot 23 \\
2 \cdot 20\end{array}$ & 1293 & $* * *$ & $\begin{array}{r}370.07 \\
20.59\end{array}$ & 1060 & $* * *$ \\
\hline D10 D17 & $\begin{array}{l}\text { Between sets } \\
\text { Within families }\end{array}$ & $\begin{array}{r}59 \\
1606\end{array}$ & $\begin{array}{r}34.86 \\
1.66\end{array}$ & 1238 & $* * *$ & $\begin{array}{r}382 \cdot 69 \\
21 \cdot 13\end{array}$ & 1068 & *** \\
\hline \multicolumn{9}{|c|}{ (ii) $\left(\bar{L}_{1 i}+\bar{L}_{2 i}+R \bar{L}_{3 i}\right)$ Comparison } \\
\hline V2 V12 & $\begin{array}{l}\text { Between sets } \\
\text { Within families }\end{array}$ & $\begin{array}{r}59 \\
1605\end{array}$ & $\begin{array}{r}44 \cdot 39 \\
2 \cdot 16\end{array}$ & 1196 & $* * *$ & $\begin{array}{r}373 \cdot 13 \\
20 \cdot 55\end{array}$ & 1071 & $* * *$ \\
\hline D10 D17 & $\begin{array}{l}\text { Between sets } \\
\text { Within families }\end{array}$ & $\begin{array}{r}59 \\
1604\end{array}$ & $\begin{array}{r}32 \cdot 39 \\
1.84\end{array}$ & 1062 & $* * *$ & $\begin{array}{r}381 \cdot 74 \\
20 \cdot 86\end{array}$ & 1080 & *** \\
\hline \multicolumn{9}{|c|}{ (iii) $\left(\bar{L}_{1 i}+\bar{L}_{2 i}+\bar{L}_{3 i}+R \bar{L}_{3 i}\right)$ Comparison } \\
\hline V2 V12 & $\begin{array}{l}\text { Between sets } \\
\text { Within families }\end{array}$ & $\begin{array}{r}59 \\
2143\end{array}$ & $\begin{array}{r}60 \cdot 43 \\
2.50\end{array}$ & 1431 & $* * *$ & $\begin{array}{r}496 \cdot 15 \\
23.91\end{array}$ & 1224 & $* * *$ \\
\hline D10 D17 & $\begin{array}{l}\text { Between sets } \\
\text { Within families }\end{array}$ & $\begin{array}{r}59 \\
2142\end{array}$ & $\begin{array}{r}47.63 \\
1.91\end{array}$ & 1471 & $* * *$ & $\begin{array}{r}533.93 \\
23.58\end{array}$ & 1336 & $* * *$ \\
\hline \multicolumn{9}{|c|}{ (iv) $\left(\bar{L}_{1 i}+\bar{L}_{2 i}\right)$ Comparison } \\
\hline V2 V12 & $\begin{array}{l}\text { Between sets } \\
\text { Within families }\end{array}$ & $\begin{array}{r}59 \\
1070\end{array}$ & $\begin{array}{r}31.83 \\
1.53\end{array}$ & 1227 & $* * *$ & $\begin{array}{r}245 \cdot 45 \\
13.90\end{array}$ & 1042 & $* * *$ \\
\hline D10 D17 & $\begin{array}{l}\text { Between sets } \\
\text { Within families }\end{array}$ & $\begin{array}{r}59 \\
1068\end{array}$ & $\begin{array}{r}19 \cdot 74 \\
1.42\end{array}$ & 820 & $* * *$ & $\begin{array}{r}234 \cdot 00 \\
15 \cdot 83\end{array}$ & 872 & $* * *$ \\
\hline \multicolumn{9}{|c|}{ (v) $\left(\bar{L}_{3 i}+R \bar{L}_{3 i}\right)$ Comparison } \\
\hline $\mathrm{V} 2 \mathrm{~V} 12$ & $\begin{array}{l}\text { Between sets } \\
\text { Within families }\end{array}$ & $\begin{array}{r}59 \\
1069\end{array}$ & $\begin{array}{r}32.09 \\
3.46\end{array}$ & 547 & $* * *$ & $\begin{array}{r}286.02 \\
33.92\end{array}$ & 497 & $* * *$ \\
\hline D10 D17 & $\begin{array}{l}\text { Between sets } \\
\text { Within families }\end{array}$ & $\begin{array}{r}59 \\
1074\end{array}$ & $\begin{array}{r}33 \cdot 09 \\
2 \cdot 41\end{array}$ & 810 & $* * *$ & $\begin{array}{r}341.95 \\
31.34\end{array}$ & 644 & $* * *$ \\
\hline
\end{tabular}

*** $P \leqq 0 \cdot 001$ 
TABLE 4

Mean squares and tests of significance for the epistasis and dominance comparisons of an $F_{\infty}$ triple test cross with dispersed $(V 2, V 12)$ and associated $(D 10, D 17)$ inbred testers

\begin{tabular}{|c|c|c|c|c|c|c|c|c|}
\hline \multirow{2}{*}{$\begin{array}{l}\text { Inbred } \\
\text { testers }\end{array}$} & \multirow[b]{2}{*}{ Item } & \multirow[b]{2}{*}{ d.f. } & \multicolumn{3}{|c|}{ Flowering time } & \multicolumn{3}{|c|}{ Final height } \\
\hline & & & MS & $x^{2}(n)$ & $P$ & MS & $X_{(n)}^{2}$ & $P$ \\
\hline \multicolumn{9}{|c|}{$\begin{array}{l}\text { Epistasis } \\
\text { (i) }\left(\bar{L}_{1 i}+\bar{L}_{2 i}-2 \bar{L}_{3 i}\right) \text { Comparison }\end{array}$} \\
\hline \multirow{2}{*}{ V2 V12 } & $\begin{array}{l}\text { Overall epistasis } \dagger \\
\text { Epistasis } \times \text { sets }\end{array}$ & $\begin{array}{r}1 \\
59\end{array}$ & $\begin{array}{r}19.61 \\
3.04\end{array}$ & $\begin{array}{r}7 \\
63\end{array}$ & NS & $\begin{array}{r}228.36 \\
40.03\end{array}$ & $\begin{array}{r}6 \\
87\end{array}$ & * \\
\hline & Within families & 1608 & $2 \cdot 85$ & & & $27 \cdot 22$ & & \\
\hline \multirow{3}{*}{ D10 D17 } & Overall epistasis & 1 & 103.97 & 21 & **** & 595.45 & 14 & **** \\
\hline & Epistasis $\times$ sets & 59 & 4.94 & 153 & **** & $41 \cdot 77$ & 93 & *** \\
\hline & Within families & 1606 & $1 \cdot 90$ & & & $26 \cdot 43$ & & \\
\hline \multicolumn{9}{|c|}{ (ii) $\left(\bar{L}_{1 i}+\bar{L}_{2 i}-2 R \bar{L}_{3 i}\right)$ Comparison } \\
\hline \multirow[t]{3}{*}{ V2 V12 } & Overall epistasis & 1 & $14 \cdot 45$ & 3 & NS & $275 \cdot 02$ & 6 & * \\
\hline & Epistasis $\times$ sets & 59 & $5 \cdot 34$ & 113 & *** & 43.79 & 95 & ** \\
\hline & Within families & 1605 & $2 \cdot 79$ & & & $27 \cdot 15$ & & \\
\hline \multirow{3}{*}{ D10 D17 } & Overall epistasis & 1 & $28 \cdot 82$ & 5 & * & $1023 \cdot 15$ & 23 & **** \\
\hline & Epistasis $\times$ sets & 59 & 5.46 & 143 & **** & $43 \cdot 29$ & 99 & $* * *$ \\
\hline & Within families & 1604 & $2 \cdot 26$ & & & $25 \cdot 90$ & & \\
\hline \multicolumn{9}{|c|}{ (iii) $\left(\bar{L}_{1 i}+\bar{L}_{2 i}-\bar{L}_{3 i}-R \bar{L}_{3 i}\right)$ Comparison } \\
\hline \multirow[t]{3}{*}{$\mathrm{V} 2 \mathrm{~V} 12$} & Overall epistasis & 1 & $24 \cdot 16$ & 6 & * & $368 \cdot 65$ & 9 & *** \\
\hline & Epistasis $\times$ sets & 59 & 3.93 & 93 & $* * *$ & $40 \cdot 17$ & 99 & *** \\
\hline & Within families & 2139 & $2 \cdot 50$ & & & 23.91 & & \\
\hline \multirow{2}{*}{ D10 D17 } & Overall epistasis & 1 & $93 \cdot 14$ & 17 & **** & $1183 \cdot 79$ & 27 & **** \\
\hline & $\begin{array}{l}\text { Epistasis } \times \text { sets } \\
\text { Within families }\end{array}$ & $\begin{array}{r}59 \\
2140\end{array}$ & $\begin{array}{l}5 \cdot 22 \\
1 \cdot 91\end{array}$ & 161 & **** & $\begin{array}{l}42.92 \\
23 \cdot 58\end{array}$ & 107 & $* * *$ \\
\hline \multicolumn{9}{|c|}{$\begin{array}{l}\text { Dominance } \\
\text { (i) }\left(\bar{L}_{1 i}-\bar{L}_{2 i}\right) \text { Comparison }\end{array}$} \\
\hline \multirow[t]{2}{*}{ V2 V12 } & Between sets & 59 & 11.98 & 462 & $* * *$ & $118 \cdot 51$ & 503 & $* * *$ \\
\hline & Within families & 1070 & $1 \cdot 53$ & & & 13.90 & & \\
\hline \multirow{2}{*}{ D10 D17 } & Between sets & 59 & 6.61 & 275 & $* * *$ & $62 \cdot 40$ & 233 & **** \\
\hline & Within families & 1068 & 1.42 & & & $15 \cdot 83$ & & \\
\hline
\end{tabular}

**** $P \leqq 0.001$ : ** $0.001<P \leqq 0.01$ : * $0.01<P \leqq 0.05$ : NS $P>0.05$.

$\dagger$ MS for 1 d.f. were tested as V.R. against the between sets MS for 59 d.f. whenever the latter were significant.

dispersed (V2 and V12) or associated (D10 and D17) inbred testers are used can be determined by the maximum likelihood procedures described by Pooni, Jinks and Pooni (1980, page 186). The $\chi^{2}$ for one degree of freedom testing these differences are given in table 5. Only three differences are significant $(P \mp 0.05)$. One is the epistasis $\times$ sets $\left(\bar{L}_{1 i}+\bar{L}_{2 i}-2 \bar{L}_{3 i}\right)$ comparison for flowering time noted earlier which is significantly larger for the associated testers. The other two are the dominance component for both characters, which are significantly smaller for the associated testers.

Finally, estimates of the additive genetic (D) and dominance components (H) derived from the various comparisons are given in table 6 along with the estimate of $\mathrm{D}$ obtained directly from the $60 \mathrm{D}$ family means. The reduction in the estimates of $H$ when associated testers are used is particularly marked but none of the estimates of $\mathrm{D}$ differ significantly from one another. 
TABle 5

Tests of significance of the differences between the $F_{\infty}$ triple test cross comparisons for the dispersed $(V 2, V 12)$ and associated $(D 10, D 17)$ inbred testers based on the goodness of fit of models which assume no difference

\begin{tabular}{|c|c|c|c|c|c|}
\hline \multirow{2}{*}{\multicolumn{2}{|c|}{ Comparison }} & \multicolumn{2}{|c|}{ Flowering time } & \multicolumn{2}{|c|}{ Final height } \\
\hline & & $x_{(1)}^{2}$ & $P$ & $x_{(1)}^{2}$ & $P$ \\
\hline \multicolumn{6}{|c|}{ Difference epistatic components } \\
\hline \multirow{2}{*}{$\left(\bar{L}_{1 i}+\bar{L}_{2 i}-2 \bar{L}_{3 i}\right)$} & Overall epistasis & 0.46 & NS & 0.20 & NS \\
\hline & Epistasis $\times$ sets & $6 \cdot 37$ & $*$ & 0.06 & NS \\
\hline \multirow[t]{2}{*}{$\left(\bar{L}_{1 i}+\bar{L}_{2 i}-2 R \bar{L}_{3 i}\right)$} & Overall epistasis & $0 \cdot 11$ & NS & 0.00 & NS \\
\hline & Epistasis $\times$ sets & 0.21 & NS & 0.01 & NS \\
\hline \multirow[t]{2}{*}{$\left(\bar{L}_{1 i}+\bar{L}_{2 i}-\bar{L}_{3 i}-R \bar{L}_{3 i}\right)$} & Overall epistasis & 0.34 & NS & $0 \cdot 27$ & NS \\
\hline & Epistasis $\times$ sets & $2 \cdot 35$ & NS & 0.08 & NS \\
\hline \multicolumn{6}{|c|}{ Difference additive genetic components } \\
\hline \multirow{4}{*}{\multicolumn{2}{|c|}{$\begin{array}{l}\left(\bar{L}_{1 i}+\bar{L}_{2 i}+\bar{L}_{3 i}\right) \\
\left(\bar{L}_{1 i}+\bar{L}_{2 i}+R \bar{L}_{3 i}\right) \\
\left(\bar{L}_{1 i}+\bar{L}_{2 i}+\bar{L}_{3 i}+R \bar{L}_{3 i}\right) \\
\left(\bar{L}_{1 i}+\bar{L}_{2 i}\right) \\
\left(\bar{L}_{3 i}+R \bar{L}_{3 i}\right)\end{array}$}} & $1 \cdot 37$ & NS & 0.01 & NS \\
\hline & & 0.78 & NS & 0.08 & NS \\
\hline & & $3 \cdot 19$ & NS & 0.05 & NS \\
\hline & & 0.06 & NS & 0.51 & NS \\
\hline $\begin{array}{l}\text { Difference dominance co } \\
\left(\bar{L}_{1 i}-\bar{L}_{2 i}\right)\end{array}$ & ponents & $4 \cdot 75$ & $*$ & 5.99 & **** \\
\hline
\end{tabular}

For $p$ values see table 4 .

TABLE 6

Estimates of additive genetic $(D)$ and dominance $(H)$ components obtained from $F_{\infty}$ triple test cross comparisons using dispersed $(V 2, V 12)$ and associated $(D 10, D 17)$ inbred testers and of the additive genetic component of the $F_{\infty}$ families $\left(\boldsymbol{P}_{i}\right)$

\begin{tabular}{|c|c|c|c|}
\hline $\begin{array}{l}\text { Inbred } \\
\text { testers }\end{array}$ & Comparison & $\begin{array}{l}\text { Flowering } \\
\text { time }\end{array}$ & $\begin{array}{c}\text { Final } \\
\text { height }\end{array}$ \\
\hline \multicolumn{4}{|c|}{ Additive genetic component } \\
\hline & $\bar{P}_{i}$ & $63 \cdot 79 \pm 12 \cdot 12$ & $372.91 \pm 70.93$ \\
\hline & $\left(\left(\dot{L}_{1 i}+\bar{L}_{2 i}+\bar{L}_{3 i}\right)\right.$ & $61 \cdot 37 \pm 11 \cdot 84$ & $465.97 \pm 90 \cdot 85$ \\
\hline \multirow{4}{*}{ V2 V12 } & $\left(\bar{L}_{1 i}+\bar{L}_{2 i}+R \bar{L}_{3 i}\right)$ & $56 \cdot 31 \pm 10 \cdot 90$ & $470 \cdot 11 \pm 91 \cdot 60$ \\
\hline & $\left(\bar{L}_{1 i}+\bar{L}_{2 i}+\bar{L}_{3 i}+R \bar{L}_{3 i}\right)$ & $58 \cdot 13 \pm 11 \cdot 16$ & $472 \cdot 24 \pm 91 \cdot 35$ \\
\hline & $\left(\tilde{L}_{1 i}+\bar{L}_{2 i}\right)$ & $60 \cdot 59 \pm 11 \cdot 72$ & $463 \cdot 09 \pm 90.39$ \\
\hline & $\left(\left(\bar{L}_{3 i}+R \bar{L}_{3 i}\right)\right.$ & $57 \cdot 26 \pm 11 \cdot 82$ & $504 \cdot 20 \pm 105 \cdot 36$ \\
\hline \multirow{5}{*}{ D10 D17 } & $\left(\left(\bar{L}_{1 i}+\bar{L}_{2 i}+\bar{L}_{3 i}\right)\right.$ & $44 \cdot 27 \pm 8 \cdot 56$ & $482.08 \pm 93.95$ \\
\hline & $\left(\bar{L}_{1 i}+\bar{L}_{2 i}+R \bar{L}_{3 i}\right)$ & $40 \cdot 73 \pm 7.95$ & $481 \cdot 17 \pm 93 \cdot 72$ \\
\hline & $\left(\bar{L}_{1 i}+\bar{L}_{2 i}+\bar{L}_{3 i}+R \bar{L}_{3 i}\right)$ & $45 \cdot 72 \pm 8 \cdot 77$ & $510 \cdot 35 \pm 98 \cdot 31$ \\
\hline & $\left(\bar{L}_{1 i}+\bar{L}_{2 i}\right)$ & $36 \cdot 62 \pm 7 \cdot 26$ & $436 \cdot 33 \pm 86 \cdot 18$ \\
\hline & $\left(\bar{L}_{3 i}+R \bar{L}_{3 i}\right)$ & $61 \cdot 36 \pm 12 \cdot 19$ & $621 \cdot 22 \pm 125 \cdot 95$ \\
\hline \multicolumn{4}{|c|}{ Dominance component } \\
\hline V2 V12 & $\left(\bar{L}_{1 i}-\bar{L}_{2 i}\right)$ & $20 \cdot 90 \pm 4.42$ & $209 \cdot 22 \pm 43 \cdot 66$ \\
\hline D10 D17 & $\left(\bar{L}_{1 i}-\bar{L}_{2 i}\right)$ & $10 \cdot 38 \pm 2 \cdot 44$ & $93 \cdot 14 \pm 23.02$ \\
\hline
\end{tabular}




\section{ConClusions}

The genetical components of variation for flowering time and final height in the V2 $\times V 12$ cross obtained from the tiple test cross using V2 and V12 as the inbred testers agree with those from previous analyses based upon an $F_{2}$ triple test cross (Jinks and Perkins, 1970, Jinks and Pooni, 1980), an $F_{\infty}$ triple test cross (Pooni, Jinks and Jayasekara, 1978), $F_{2}$ and backcross families (Pooni and Jinks, 1982) and $F_{3}$ families (Jinks and Pooni, 1980). There are, however, significant differences between the two $\mathrm{F}_{\infty}$ triple test crosses described in this paper attributable to the use, for the first time, of relatively associated inbred testers, D10 and D17, which results in the halving of the dominance components (tables 4 and 6). From the theoretical expectations in table 2 and the diagnostic tests based upon them (section 2) it is clear that this halving of $\mathrm{H}$ must be due to a linkage disequilibrium arising from an excess of repulsion linkages between alleles whose dominance deviations have the same sign.

Epistasis of the $i, j$ and 1 types is detected by the appropriate comparisons in both triple test crosses but with higher levels of significance where the associated testers, D10 and D17, are used (table 4). There are, however, no significant differences between the estimates of the additive genetic component that could be attributed to the type of testers. On the basis of the diagnostic tests in section 2 there is, therefore, no evidence that the linkage disequilibrium involves alleles that are displaying nonallelic interactions. This conclusion must reflect the relative insensitivity of the test since there is evidence of repulsion linkages between loci at which there are non-allelic interactions for flowering time and final height in the V $2 \times$ V12 cross (Pooni and Jinks, 1982).

That the insensitivity resides in the test rather than in the data will be shown by analyses presented in a further paper where the information from the two triple test crosses is combined rather than contrasted to illustrate the influence of allele distribution between the inbred testers.

\section{REFERENCES}

JAYASEKARA, N. E. M. AND JINKS, J. L. 1976. Effect of gene dispersion on estimates of components of generation means and variances. Heredity, 36, 31-40.

JINKS, J. L., JAYASEKARA, N. E. M. AND BOUGHEY, H. 1977. Joint selection for both extremes of mean performance and of sensitivity to a macro-environmental variable. II. Single seed descent. Heredity, 39, 345-355.

JINKS, J. L. AND PERKINS, J. M. 1970. A general method for the detection of additive, dominance and epistatic components of variation. III. $F_{2}$ and backcross populations. Heredity, 25, 419-429.

JINKS, J. L. AND POONI, H. S. 1980. Comparing predictions of mean performance and environmental sensitivity of recombinant inbred lines based upon $F_{3}$ and triple test cross families. Heredity, 45, 305-312.

KEARSEY, M. J. AND JINKS, J. L. 1968. A general method for the detection of additive, dominance and epistatic components of variation for metrical traits. I. Theory. Heredity, $23,403-409$.

MATHER, K. AND JINKS. J. L. 1982. Biometrical Genetics (Third edition). Chapman and Hall, London.

POONI, H. S. AND JINKS, J. L. 1982. Comparative analysis of association and dispersion crosses to detect linkage and epistatic components of variation. Heredity, 49, 211-220. 
POONI, H. S., JINKS, J. L. AND JAYASEKARA, N. E. M. 1978. An investigation of gene action and genotype $\times$ environmental interaction in two crosses of Nicotiana rustica by triple test cross and inbred line analysis. Heredity, 41, 83-92.

POONI, H. S., JINKS, J. L. AND POONI, G. S. 1980. A general method for the detection and estimation of additive, dominance and epistatic variation for metrical traits. IV. Triple test cross analysis for normal families and their selfs. Heredity, 44, 177-192. 